This is an author produced version of a paper published in Digestive Diseases and Sciences. This paper has been peer-reviewed but does not include the final publisher proof-corrections or journal pagination.

Citation for the published paper:

Hakansson, A and Stene, C and Mihaescu, A and Molin, G and Ahrné, S and Thorlacius, $\mathrm{H}$ and Jeppsson, B

"Hip and Lactobacillus plantarum DSM 9843 Reduce Ischemia/Reperfusion Injury in the Mouse Colon"

Digestive Diseases and Sciences, 2006, Issue: Sep 29. http://dx.doi.org/10.1007/s10620-006-9170-9

Access to the published version may require journal subscription. Published with permission from: Springer 


\title{
Rose Hip and Lactobacillus plantarum DSM 9843 Reduce Ischemia/Reperfusion Injury in the Mouse Colon
}

\section{Rose Hip \& Lactobacillus in Colon Injury}

Original Article

\author{
Å. Håkansson, $\mathrm{MSc}^{1}$, C. Stene, $\mathrm{MD}^{2}$, A. Mihaescu, $\mathrm{MD}^{2}, \mathrm{G}$. Molin, $\mathrm{PhD}^{1}$, S. Ahrné, \\ $\mathrm{PhD}^{1}, \mathrm{H}$. Thorlacius, $\mathrm{MD}, \mathrm{PhD}^{2}$ and $\mathrm{B}$. Jeppsson, $\mathrm{MD}, \mathrm{PhD}^{2}$. \\ ${ }^{1}$ Food Hygiene, Department of Food Technology, Engineering and Nutrition, Lund \\ University, Lund, Sweden \\ ${ }^{2}$ Department of Surgery, Malmö University Hospital, Lund University, Malmö, Sweden \\ * Authors contributed equally
}

Corresponding author: Professor Bengt Jeppsson, Department of Surgery, Malmö University Hospital, Lund University, SE 20502 Malmö, Sweden. Tel: +46-40-333760; Fax: +46-40-927877; e-mail: bengt.jeppsson@med.lu.se

Presented in part at the XXXIX Congress of the European Society for Surgical Research in Athens, Greece, May 12-15, 2004.

Acknowledgement of support: Cancer Foundation, Dir. A. Påhlsson’s Foundation, Gunnar Nilsson's Foundation, Malmö University Hospital, Apotekare Hedberg's Foundation, Bengt Ihre's Foundation, Ruth and Richard Juhlin's Foundation, Einar and Inga Nilsson's Foundation and Agnes Nilsson's Foundation. 


\section{Abstract}

Purpose: Ischaemia/reperfusion (I/R) of the colon is an inflammatory condition leading to tissue injury where reactive oxygen species play a central role. Rose hip is rich in biologically active polyphenols with antioxidative properties, which may be important in prevention of lipid peroxidation. L. plantarum DSM 9843 possesses enzymatic activity towards polyphenols. The objective of this study was to define the effect of oral administration of L. plantarum and rose hip in I/R injury.

Results: Administration of rose hip and L. plantarum significantly decreased MDA levels in caecum tissue and Enterobacteriaceae counts in caecum stool. A positive correlation between MDA levels and Enterobacteriaceae counts was found.

Conclusions: The results support a synergistic/additive role of rose hip and L. plantarum in reducing lipid peroxidation. Therefore rose hip and $L$. plantarum may be used as a pretreatment to tissue injuries, e.g. colonic surgery, organ transplantation and vascular surgery.

Key words: ischaemia, reperfusion, rose hip, polyphenols, lactobacilli. 


\section{Introduction}

The epithelial cells of the gastrointestinal mucosa form a physical barrier between the internal milieu of the body and the constituents of the gut luminal flora. The colonic mucosa harbors a huge bacterial load and plays a fundamental role in sustaining the physical barrier against translocation of potentially pathogenic bacteria and noxious substances from the luminal content (1). The commensal bacteria are harmless and even beneficial under normal circumstances, but may cause local or systemic inflammatory disease if the integrity of the host surface is disturbed (2). Ischaemia and reperfusion (I/R) of the intestinal tract disturbs the barrier function, causing sepsis (3) and ultimately multiple organ failure.

A rate-limiting step in the pathophysiology of I/R is the activation and recruitment of leukocytes $(4,5)$. Activated leukocytes release toxic products, such as reactive oxygen species (ROS), proteases and vasoactive substances, which in turn cause tissue damage by lipid peroxidation and oxidation of enzymes, a massive protein oxidation, degradation and organ dysfunction $(6,7)$.

The prevention of lipid peroxidation is an essential process in all aerobic organisms, as lipid peroxidation products can cause DNA damage (8). It is therefore of high interest to find antioxidant substances with the ability to scavenge ROS.

Among the various natural scavengers of these reactive molecule activities, polyphenols have received attention. These compounds, widely distributed in plants, constitute an important class of antioxidative natural substances (9). Rose hip possesses antioxidant properties which often have been attributed to vitamin C, known to be an effective 
antioxidant. However, it was demonstrated that the antioxidant properties of rose hip are not due only to ascorbic acid, but also to polyphenols (10). Rose hip extract has also been shown to inhibit the chemotaxis and oxidative burst response of the human peripheral blood polymorphonuclear leucocytes in vitro, this effect was not due to vitamin $\mathrm{C}$ content of the extract (11).

It is well known that polyphenols can be toxic and bacteriostatic (12). Nevertheless, some bacteria are quite resistant to polyphenols and may degrade many phenolic compounds (13). Most Lactobacillus spp. are unable to degrade polyphenols, but strains of the closely related species Lactobacillus plantarum, Lactobacillus pentosus and Lactobacillus paraplantarum possess tannase activity (14) - tannins are naturally occurring water soluble polyphenols - and metabolise phenolic acids (15). Lactobacilli constitute an integral part of the healthy gastrointestinal microecology and are involved in host metabolism offering nutritional and therapeutic benefits (16), having abilities to minimize the harmful effects of potentially pathogenic microbes (17) and stimulating immune response (18). In contrast, Enterobacteriaceae is a genetically close family which includes Escherichia coli and pathogenic taxa as Shigella and Salmonella and where even normally non-pathogenic taxa have a strong pro-inflammatory capacity due to bacterial lipopolysaccharide (LPS). LPS or endotoxin is present in almost all Gram-negative bacteria (19) and triggers the release of numerous inflammatory mediators such as ROS (20).

The objective of this study was to define the effect of oral supplementation of L. plantarum DSM 9843 and rose hip. It was hypothesized that the administered strain, 
in the GI-tract, may convert the polyphenols of rose hip to compounds with antiinflammatory capacity. Alternative actions may be an additive suppression of inflammation by immunological effects of bacteria and antioxidative effects of the polyphenols in rose hip. A mouse model was used to study I/R induced injury and the level of lactobacilli and Enterobacteriaceae in the caecum. 


\title{
Methods
}

\begin{abstract}
Animals
Male Balb/cJ mice (Taconic, Denmark), weighing approximately 20 g, were kept under standard laboratory conditions and maintained on 12 hours light and 12 hours dark cycle. They were acclimatized one week before use and were allowed free access to animal chow (nonradiated R3, [Lactamin, Sweden]) and tap water. All experimental procedures were performed in accordance with legislation on the protection of animals and were approved by the Committee of Ethics of animal experiments at Lund University.
\end{abstract}

\section{Experimental protocol}

The animals were randomly divided into 6 groups of 9 animals in each and each animal was placed in its own cage with food dish. The cages were carefully separated so that contamination could not occur. After 7 days of acclimatisation the mice were fed experimental diet for 7 days. They were weighed after acclimatisation and before sacrifice. The feed was dissolved in water to soften the consistency (experimental diet) prior to the addition of supplementation. The mice were divided into the following groups and each group of animals was fed experimental diet and supplementation: I/R-only group with ischaemia/reperfusion injury given supplementary carbohydrates, I/R-group given rose hip (Rh), I/R-group given L. plantarum and carbohydrates (Lp), 
I/R-group given rose hip and L. plantarum (Rh+Lp), I/R-group given vitamin C and carbohydrates (Vit C), and a No-I/R group without I/R injury but given supplementary carbohydrates. 1 ml suspension of L. plantarum DSM 9843 (109 CFU/mouse), rose hip powder (1.6 g/mouse) or vitamin C (0.014 g/mouse) was added to the experimental diet in the above mentioned groups each day.

Supplementary carbohydrates (fructose and glucose, $0.65 \mathrm{~g}$ of each/mouse) were added to the groups indicated above to compensate for the carbohydrate supply of rose hip.

\section{Bacterial strain}

The bacterial strain used in the experiment was Lactobacillus plantarum DSM 9843 (= strain 299v) which had been isolated from colon from a healthy person and has ability to colonise the human intestinal mucosa after oral administration $(21,22)$.

\section{Rose hip}

Rose hip powder was kindly supplied by Skane Dairy, Malmö, Sweden, and contained $863 \mathrm{mg} / 100 \mathrm{~g}$ of natural vitamin C and $81.8 \mathrm{~g} / 100 \mathrm{~g}$ of carbohydrates as analysed by Steins laboratory, Lund, Sweden. 


\section{Anaesthetic and surgical preparation}

The mice were anaesthesised with 7.5 mg Ketamine (Ketalar ${ }^{\circledR} 50$ mg/ml, [Pfizer, UK]) and $2.5 \mathrm{mg}$ Xylazine (Narcoxyl® $20 \mathrm{mg} / \mathrm{ml}$, [Veterinaria AG, Schweiz]) per 100 g body weight by intraperitoneal injection. The animals were placed on a warming pad $\left(37^{\circ} \mathrm{C}\right)$ for maintenance of body temperature. A midline abdominal incision was made. Surgery was performed with careful attention to sterile technique. The superior mesenteric artery was identified and occluded using a vessel clamp, resulting in ischaemia of small intestine and colon. 1.0 ml Dulbecco’s PBS (Dulbecco's phosphate buffered saline, [Sigma]), (pH 7.2-7.3), was given into the peritoneal cavity for fluid resuscitation. The artery was occluded for 30 minutes then the clamp was removed. The tissue was observed for immediate reperfusion. Next the abdomen was closed using a running Vicryl 4-0 suture (Johnson \& Johnson, USA). The animal was allowed to awake from anaesthesia and was removed from the warming pad and placed back into the cage. After 240 minutes, the animal was given anaesthesia again (23) and tissue and stool samples were obtained in the following order and placed in preweighed tubes: caecum stool sample and caecum tissue sample for MDA586 TM (colorimetric assay for lipid peroxidation); samples for bacterial evaluation were weighed and collected in sterile tubes containing $3 \mathrm{ml}$ of freezing media and frozen immediately at $-70^{\circ} \mathrm{C}$ for later evaluation. Samples for MDA586 TM were rinsed in ice cold Dulbecco's PBS, weighed, homogenized, alliquoted, and then frozen immediately at $-70^{\circ} \mathrm{C}$ for later evaluation. Caecum was cut by its anatomical borders, i.e. the ampoule of colon and the rotund sac. 


\section{Histopathological study}

Seven to eight millimetre samples of caecum were obtained and placed in phosphate buffered 4 per cent formaldehyde, fixated over night and dehydrated. Paraffin-embedded samples were cut and studied under light microscopy after staining with H \& E (Hematoxylin-Eosin). At least eight samples from each group were analysed.

\section{Determination of intestinal microflora}

The samples were placed in ultrasonic bath for 5 minutes and swirled for 2 minutes. Viable cell samples $(1 \mathrm{ml})$ were serially diluted in dilution liquid (sodium chloride [Merck], 8.5 g/l; Bacteriological peptone [Oxoid, Unipath LTD, Basingstoke, Hampshire, England], 1 g/l; Tween 80 [Merck], 1 g/l; L - Cystine hydrochloride monohydrate [Merck], $0.2 \mathrm{~g} / \mathrm{l}$ ) and $0.1 \mathrm{ml}$ of the samples from the appropriate dilutions were spread plated. Viable counts were obtained from Rogosa agar (Oxoid) that was incubated anaerobically at 37oC for 72 hours (lactobacilli counts) and from violet redbile-glucose agar VRBG (Oxoid) that was incubated aerobically at 37oC for 24 hours (Enterobacteriaceae counts). 


\section{Lipid peroxidation}

Caecal content of malondialdehyde (MDA) was determined as an index of lipid peroxidation, using MDA 586TM (Oxis International Inc. Portland, Oregon, USA), a colorimetric assay designed to quantify MDA. Caecal tissues were collected, weighed, rinsed in ice cold Dulbecco's PBS and homogenised in 1 ml Dulbecco's PBS with 5 mM butylated hydroxytoluene. After homogenisation the samples were centrifuged at $4000 \mathrm{x}$ $\mathrm{g}$ for 10 minutes at $4 \mathrm{oC}$. The supernatants were stored at $-70 \mathrm{oC}$ until determination. Lipid peroxidation was estimated by adding an aliquot (200 $\mu \mathrm{l})$ of the supernatant to a reaction mixture containing $640 \mu \mathrm{l}$ of N-methyl-2-phelindole, $10 \mu \mathrm{l}$ probucol and $150 \mu \mathrm{l}$ of $12 \mathrm{M}$ hydrochloric acid. The samples were then incubated in a water bath for 60 minutes at $45 \mathrm{oC}$ and centrifuged at $10000 \mathrm{x}$ g for 10 minutes at $4 \mathrm{oC}$. The absorbance of the supernatant was measured by spectrophotometry at $586 \mathrm{~nm}$. Tetramethoxypropane (TMOP) was used as a MDA standard because MDA is not stable. TMOP is hydrolysed during the acid incubation step at 45oC, which will generate MDA. The results were expressed as nmol MDA.

\section{Statistics}

All values are presented as median (25-75 percentiles). All statistical analyses were conducted in SigmaStat version nr 2.0 (SPSS Inc.). Differences between all groups were evaluated by Kruskal-Wallis test. When comparing only two groups Mann-Whitney rank 
sum test was used. The correlation between expectations of benefit was ascertained using the Pearson correlation coefficient. P-values $<0.05$ were considered significant. 


\section{Results}

\section{Characteristics of mice during study}

All animals tolerated the products well and no adverse events were reported during the period of intake. The weight of mice at the beginning of the treatments was: 23.5 (22.524.5) g in I/R-only group, 24.0 (23.0-25.0) g in Rh group, 24.0 (23.0-24.5) g in Lp group, 24.0 (23.0-25.0) g in Rh+Lp group, 24.0 (22.8-25.0) g in Vit C group and 24.0 (23.024.3) $\mathrm{g}$ in No-I/R group. The weight of mice after one week of treatment and before sacrifice was: 27.0 (26.0-28.0) g in I/R-only group, 26.0 (26.0-28.0) g in Rh group, 26.0 (25.5-28.0) g in Lp group, 28.0 (26.0-28.0) g in Rh+Lp group, 26.0 (24.0- 26.5) g in Vit C group and 26.0 (26.0-28.0) $\mathrm{g}$ in No-I/R group.

\section{Rose hip and L. plantarum DSM 9843 in I/R-induced tissue injury}

Reperfusion of ischaemic caecum caused an increase in the caecal MDA concentration (Fig. 1, Table 1). A statistically significant difference in MDA concentration was found between the I/R-only group compared to the No-I/R group (Fig. 1, Table 1).

Pretreatment with rose hip and L. plantarum DSM 9843 significantly reduced the tissue MDA level after I/R injury compared to I/R-only group. A statistically significant difference was also found when the group supplemented with rose hip and L. plantarum 
DSM 9843 in combination was compared with the groups that were supplemented with vitamin C or bacteria alone (Fig. 1, Table 1).

No statistically significant difference was found between the group that received only rose hip compared to the group that received bacteria and rose hip in combination, but notably the group that received bacteria and rose hip showed a decreased level of MDA in comparison to the group that received rose hip alone. Vitamin C (in crystalline form) had no effect in decreasing the concentration of MDA (Fig. 1, Table 1).

\section{Caecal bacterial counts}

Administration of the L. plantarum strain resulted in a small increase in total lactobacilli count in the group supplemented with bacteria and rose hip in combination. The mean value was 8.9 (8.4 - 9.1) log CFU/g of faeces compared to the other groups with mean values ranging from $8.3(8.2-8.9)$ to $8.8(8.5$ - 9.0) log CFU/g of faeces. No statistical significance in changes of lactobacilli count was found.

The Enterobacteriaceae count decreased significantly in the group supplemented with bacteria and rose hip in combination compared to the I/R-only group, the group that received only bacteria and to the vitamin C group (Fig. 2). The difference between the rose hip alone group and the group with rose hip and bacteria in combination was not statistically significant.

The incidence of Enterobacteriaceae count where no colonies were detected at the lowest plate count dilution ( $<0 \mathrm{CFU} / \mathrm{g}$ caecal content per animal) for the different groups were 0/8 for the I/R-only group, 0/9 for the No-I/R group, $1 / 8$ for the L. plantarum group, 1/9 
for the vitamin $C$ group, 3/9 for the rose hip alone group and 4/9 for the combination of rose hip and $L$. plantarum. There was only a small difference in caecal Enterobacteriaceae count between I/R-only group and No-I/R group.

\section{Correlation analysis}

A significant linear relationship between the Enterobacteriaceae counts (log CFU/g) and the MDA values (nmol/g) was observed, with a correlation coefficient (Pearson) $r=0.3$, $(\mathrm{p}<0.05)$.

\section{Caecum histology}

The histological evaluation in $\mathrm{H} \& \mathrm{E}$ shows differences between groups. A severe diffuse injury indicated by mucosal damage, edema and congestion in the I/R-only group and much milder changes in treatment groups and among them the less damage was found in the group treated with rose hip and L. plantarum in combination (Fig. 3A-B). 


\section{Discussion}

Pretreatment with rose hip and L. plantarum DSM 9843 significantly attenuated the generation of caecal MDA in response to I/R injury. The tissue MDA was increased after 30 minutes of ischaemia followed by 240 minutes of reperfusion, indicating a substantial yield of ROS-induced damage in this colonic model of I/R. These findings suggest that the combination of rose hip and L. plantarum DSM 9843 reduced the production of ROS in the colon.

Lactobacillus is an important part of the intestinal microflora and plays a significant role in colonization resistance (24). It has been shown that certain diseases and stress are associated with reduction of the intestinal Lactobacillus population $(25,26)$ and supplementation with these bacteria improves the overall condition, showed both in experimental and clinical studies $(27,28)$. Oral administration of L. plantarum DSM 9843, with known probiotic properties (29), and rose hip in combination is accompanied by a significant decrease in the number of Enterobacteriaceae. This must be regarded as beneficial because the family Enterobacteriaceae, in general, is pro-inflammatory and also includes many potentially pathogens. The beneficial effect might be mediated by the high antimicrobial effect from polyphenols of rose hip and from the supplemented Lactobacillus strain, which is known to inhibit the growth of various potentially pathogenic bacteria $(22,30)$.

Brown et al. demonstrated that administration of LPS caused an elevated level of lipid peroxidation, measured as the amount of MDA in colonic tissue (31). In the present study, we found a positive correlation between the level of MDA in caecal tissue and 
Enterobacteriaceae counts in caecal stool, which indicates an association.

It was shown that administration of Lactobacillus improved mucosal protein as well as DNA- and RNA-content in colon of methotrexate-induced enterocolitis rats (32). Intestinal lactobacilli may even play a role in maintaining gastrointestinal epithelial proliferation and function (33).

To evaluate the antioxidative effect of the vitamin $\mathrm{C}$ in rose hip, equal levels of vitamin C contained in rose hip was administrated to one of the groups. Pretreatment with vitamin C did not decrease either the production of MDA or the level of Enterobacteriaceae, which might use vitamin $\mathrm{C}$ as carbon- and energy source. This effect is not attained from the vitamin C naturally occurring in rose hip, maybe since the polyphenols in rose hip are bacteriostatic and inhibit bacterial growth. L. plantarum DSM 9843, on the contrary, possesses tannase activity (17). Thus, these bacteria are able to grow in environments containing polyphenols.

The results obtained from experiments on conventional animals may not be applicable to the human gut ecosystem, because the microflora of these animals differs in composition from that of humans (34). The lactobacilli is a major group in the intestinal microbiota of mice (35), which is not the case in humans where lactobacilli regularly are present but in a smaller proportion of the microflora $(36,37)$. The tannase activity of the lactobacilli naturally occurring in mice is not clarified. This might be an explanation why the results did not show significant difference between the group supplemented with rose hip and bacteria in combination, compared to the group supplemented with rose hip alone. 
However, this must be further elucidated. In a clinical situation this difference between these two groups is expected to be more pronounced because lactobacilli is more prominent in mice than in humans.

In conclusion, our present study demonstrates that administration of L. plantarum DSM 9843 and rose hip in combination decreases the production of MDA in caecum in response to I/R injury and it also inhibits the growth of Enterobacteriaceae. Considering its safety (11), loss of adverse effects, low price and ease of administration, this indicates a role of rose hip and L. plantarum DSM 9843 in combination as a pretreatment to diminish lipid peroxidation and tissue injuries in fields of e.g. colonic surgery, organ transplantation and vascular surgery and in clinical conditions where I/R injury accounts. 


\section{Acknowledgements}

Susanne Eiswohld and Diya Adawi for technical support; Jonas Björk, biostatistician, Competence Center for Clinical Research, Lund University Hospital for statistical analysis and Virgil Gadaleanu, Dept. of Pathology, Malmö University Hospital, for histological examination, are all gratefully acknowledged. 


\section{References}

1. Berg RD: Bacterial translocation from the gastrointestinal tract. Adv Exp Med Biol 473:11-30, 1999

2. Hornef MW, Wick MJ, Rhen M, Normark S: Bacterial strategies for overcoming host innate and adaptive immune responses.

Nature immunology 3:1033-1040, 2002

3. Carden DL, Granger DN: Pathophysiology of ischaemia-reperfusion injury.

J Pathol 190:255-266, 2000

4. Carlos TM, Harlan JM: Leukocyte endothelial adhesion molecules.

Blood 84:2068-2101, 1994

5. Panes J, Perry M, Granger DN: Leukocyte endothelial cell adhesion: Avenues for therapeutic intervention. Br J Pharmacol 126:527-550, 1999

6. Cetincale O, Bilgic L, Bolayirli M, Sengul R, Ayan F, Burcak G: Involvement of neutrophils in ischemic injury: Biochemical and histopathological investigation of the effects of FK506 on dorsal skin flaps in rats.

Ann Plast Surg 39:505-515, 1997

7. Weiss SJ: Tissue destruction by neutrophils. N Eng J Med 320:365-376, 1989

8. Matés JM, Pérez-Gómez C, Núñez de Castro I: Antioxidant enzymes and human diseases. Clin Biochem 32(8):595-603, 1999

9. Jovanovic SV, Steenken S, Tosic M, Marjanovic B, Simic MG: Flavonoids as antioxidants. J Am Chem Soc 4846-4851, 1994

10. Daels-Rakotoarison DA, Gressier B, Trotin F, Brunet C, Luyckx M, Dine T, 
Bailleul F, Cazin M, Cazin J-C: Effects of Rosa canina fruit extract on neutrophil respiratory burst. Phytother Res 16:157-161, 2002

11. Kharazmi A, Winther K: Rose hip inhibits chemotaxis and chemiluminescence of human peripheral blood neutrophils in vitro and reduces certain inflammatory parameters in vivo. Inflammopharmacology 7:377-386, 1999

12. Scalbert A: Antimicrobial properties of tannins.

Phytochemistry 30:3875-3883, 1991

13. Descamps AM: Microbial degradation of tannins and related compounds. In Plant Cell Wall Polymer Biogenesis and Biodegradation. NG Lewis, MG Paice (eds). Washington DC, American Chemical Society, 1989, pp 559-566

14. Osawa R, Kuroiso K, Goto S, Shimzu A: Isolation of tannin-degrading lactobacilli from humans and fermented foods.

Appl Environ Microbiol 66:3093-3097, 2000

15. Barthelmebs L, Divies C, Cavin J-F: Knockout of the p-coumarate decarboxylase gene from Lactobacillus plantarum reveals the existence of two other inducible enzymatic activites involved in phenolic acid metabolism. Appl Environ Microbiol 66:3368-3375, 2000

16. Fernandes CF, Shahani KM, Amer MA: Therapeutic role of dietary lactobacilli and lactobacilli fermented dairy products.

FEMS Microbiol Rev 46:343-356, 1987

17. Shahani KM, Ayebo AD: Role of dietary lactobacilli in gastrointestinal microecology. Am J Clin Nutr 33:2448-2457, 1980

18. Marteau P, Rambaud JC: Potential of using lactic acid bacteria for therapy and 
immunomodulation in man. FEMS Microbiol Rev 12:207-220, 1993

19. Mayeux PR: Pathobiology of lipopolysaccharide.

J. Toxicol. Environ. Health 51:415-435, 1997

20. Victor VM, De la Fuente M: Several functions of immune cells in mice changed by oxidative stress caused by endotoxin.

Physiol Res 52:789-796, 2003

21. Molin G, Jeppsson B, Ahrné S, Johansson ML, Nobaeck S, Ståhl M, Bengmark S: Numerical taxonomy of Lactobacillus spp. associated with healthy and diseased mucosa of the human intestines.

Journal of Applied Bacteriology 74:314-323, 1993

22. Johansson ML, Molin G, Jeppsson B, Nobaek S, Ahrné S, Bengmark S:

Administration of different Lactobacillus strains in fermented oatmeal soap: In vivo colonization of human intestinal mucosa and effect on the indigenous flora. Appl Environ Microbiol 59:15-20, 1993

23. Riaz AA, Thorlacius H: Oxygen radical-dependent expression of CXC chemokines regulate ischemia/reperfusion-induced leukocyte adhesion in the mouse colon. Free Radic Biol Med 35(7):782-789, 2003

24. Van deer Weeij D, Berghuis JM, Lekkerkerk JEC: Colonization resistance of the digestive tract of the mice during systemic antibiotic treatment.

J Hyg 70(4):605-609, 1972

25. Fabia R, Ar-Rajab A, Johansson ML, Andersson R, Willen R, Jeppsson B, Molin G, Bengmark S: Impairment of bacterial flora in human ulcerative colitis and experimental colitis in rats. Digestion 54:248-255, 1993 
26. Tannock GW, Savage DC: Influences of dietary and environmental stress on microbial populations in the murine gastrointestinal tract. Infection and Immunity 9:591-598, 1974

27. Fabia R, Ar-Rajab A, Johansson ML, Andersson R, Willen R, Jeppsson B, Molin G, Bengmark S: The effect of exogenous administration of Lactobacillus reuteri R2LC and oat fiber on acetic acid induced colitis in the rat. Scand J Gastroenterol 28:155-162, 1993 28. Gorbach SL, Chang TW, Goldin B: Successful treatment of relapsing C. difficile colitis with Lactobacillus GG. Lancet 2(8574):1519, 1987

29. Nobaeck S, Johansson ML, Molin G, Ahrné S, Jeppsson B: Alteration of intestinal microflora is associated with reduction in abdominal bloating and pain in patients with irritable bowel syndrome.

Am J Gastroenterol 95:1231-1238, 2000

30. Adawi D, Kasravi FB, Molin G, Jeppsson B: Effect of Lactobacillus supplementation with and without arginine on liver damage and bacterial translocation in an acute liver injury model. Hepatology 25:642-647, 1997

31. Brown JF, Chafee KA, Tepperman BL: Role of mast cells, neutrophils and nitric oxide in endotoxin-induced damage to the neonatal rat colon.

British Journal of Pharmacology 123:31-38, 1998

32. Mao Y, Nobaek S, Kasravi B, Adawi D, Stenram U, Molin G, Jeppsson B: The effects of Lactobacillus strains and oat fiber on methotrexate-induced enterocolitis in rats. Gastroenterology 111:334-344, 1996 
33. Goodlad RA, Wright NA: Changes in intestinal cell proliferation, absorptive capacity and structure in young, adult and old rats.

J Anatomy 173:109-118, 1990

34. Imaoka A, Setoyama H, Takagi A, Matsumoto S, Umesaki Y: Improvement of human faecal flora-associated mouse model for evaluation of the functional foods. Journal of Applied Microbiology 96:656-663, 2004

35. Savage DC, Dubos R, Schaedler RW: The gastrointestinal epithelium and its autochthonous bacterial flora. J Exp Med 127(1):67-76, 1968

36. Suau A, Bonnet R, Sutren M, Godon JJ, Gibson GR, Collins MD, Dore J: Direct analysis of genes encoding 16S rRNA from complex communities reveals many novel molecular species within the human gut.

Appl Environ Microbiol 65:4799-4807, 1999

37. Wilson KH, Blictchington RB: Human colonic biota studied by ribosomal DNA sequence analysis. Appl Environ Microbiol 62:2273-2278, 1999 


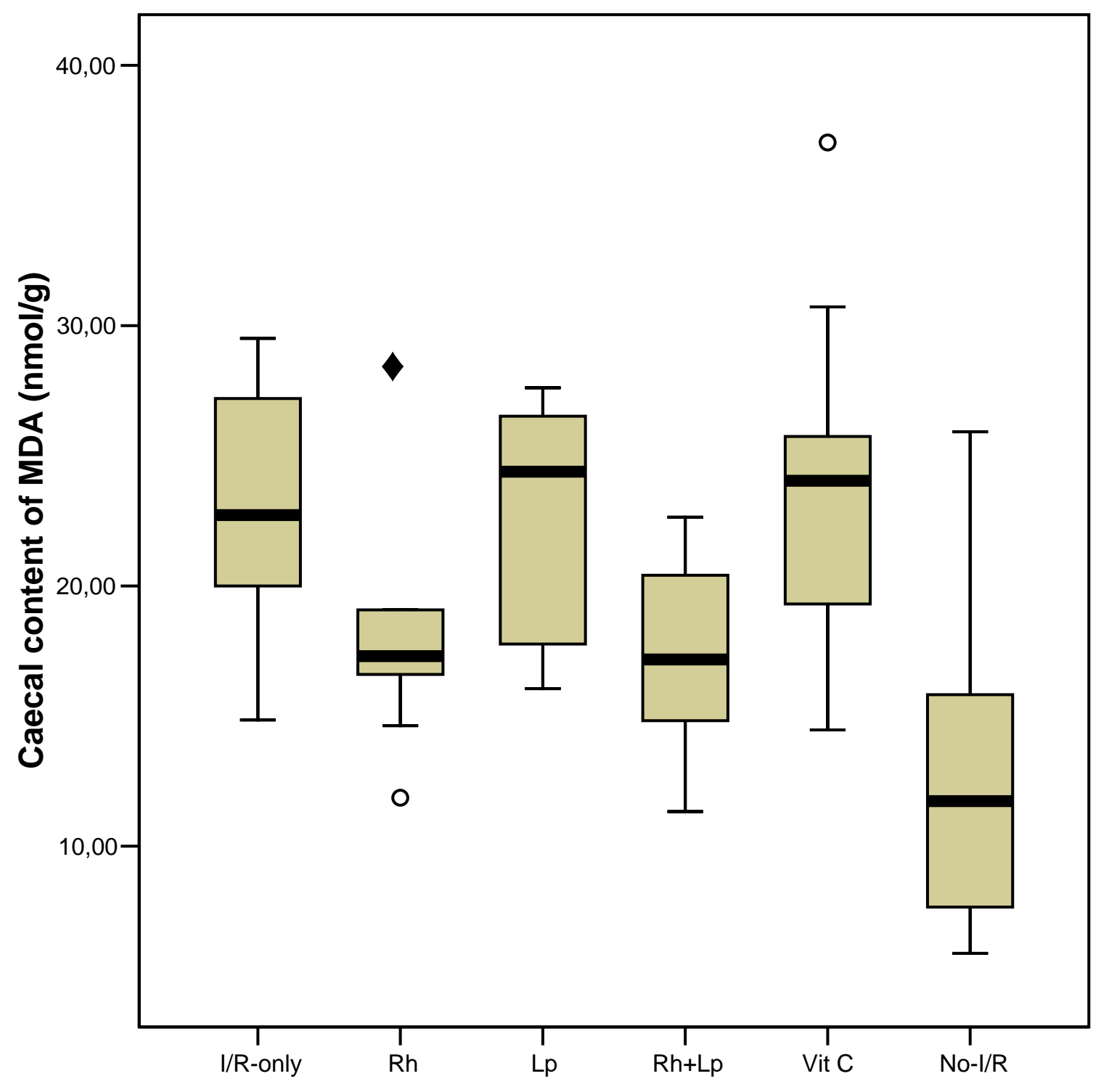




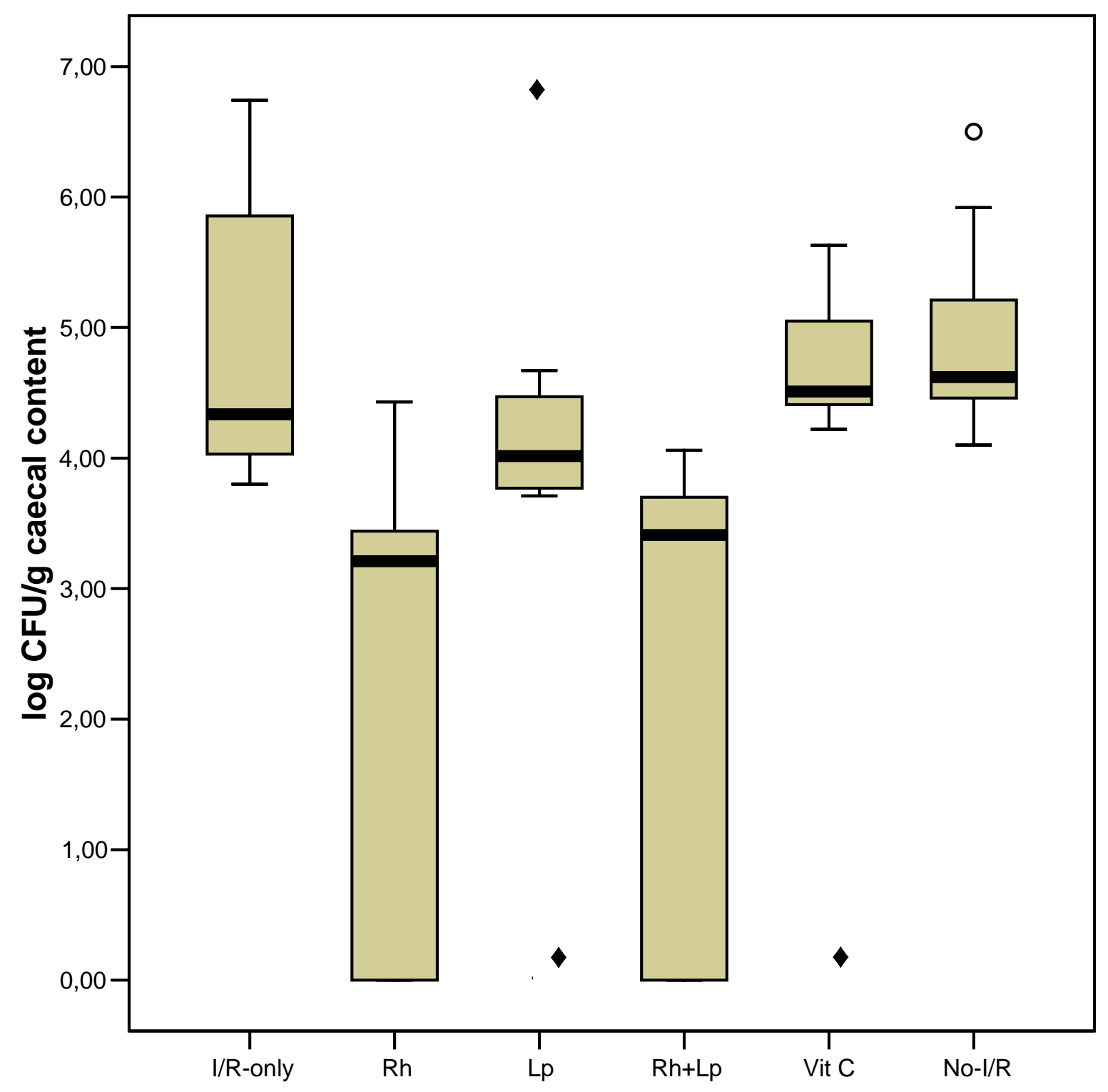




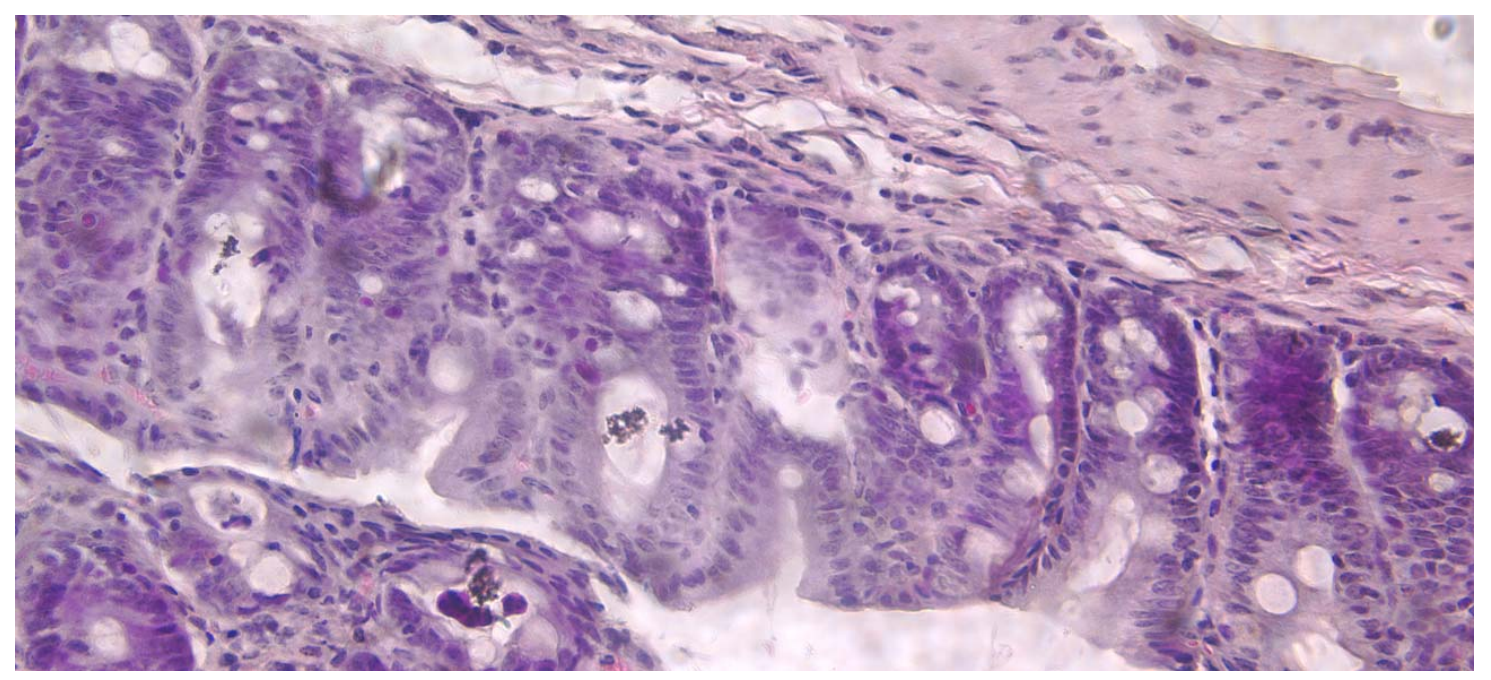




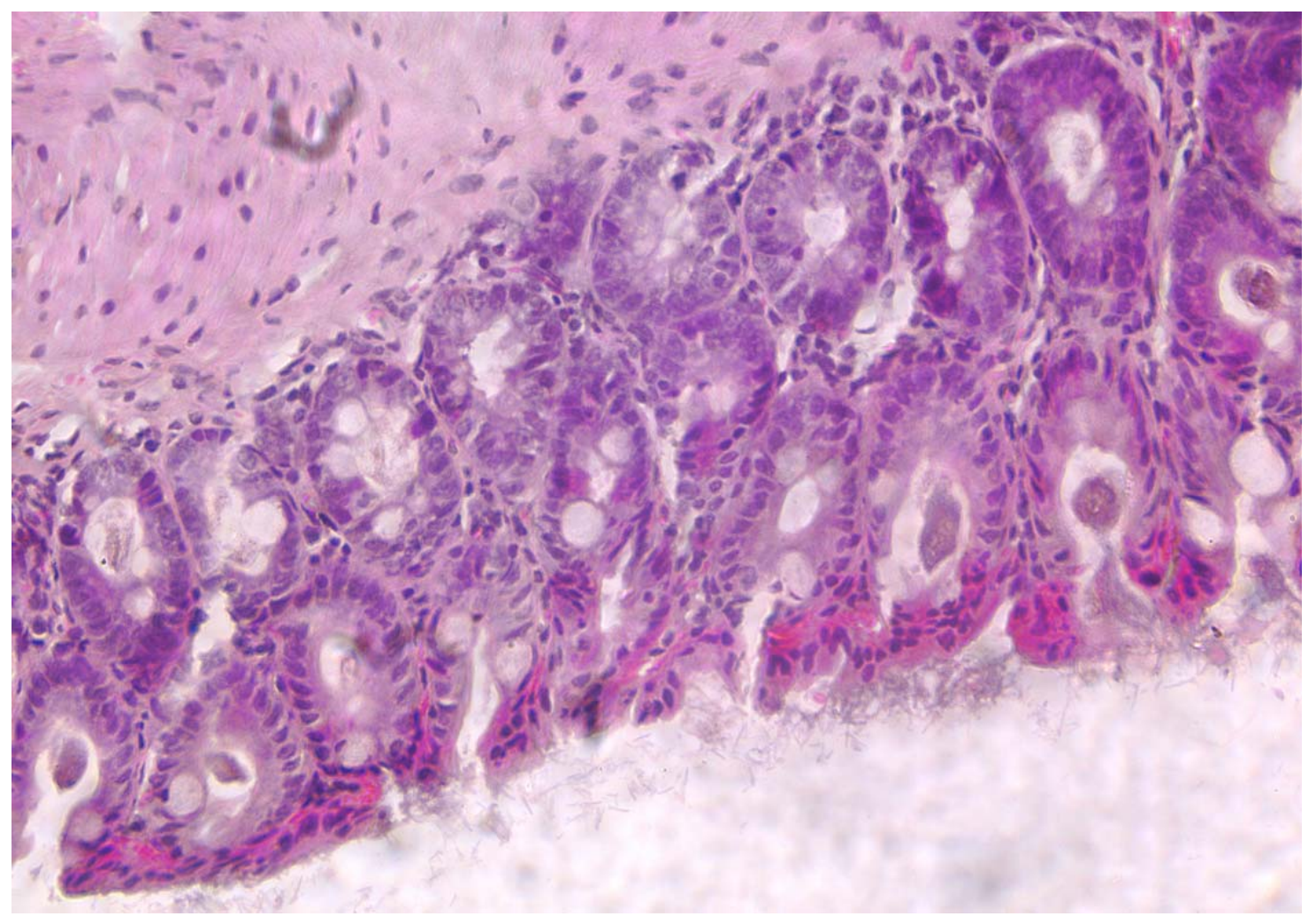


Table 1. Caecal tissue content of MDA (nmol/g)

as median with range

Group MDA (nmol/g)

I/R-only (n=8)

22.7 *

(20.0-27.2)

$\mathrm{Rh} \quad(\mathrm{n}=9)$

17.3

(16.1-21.7)

Lp $\quad(n=8)$

24.4

(17.8-26.5)

$\mathbf{R h}+\mathbf{L p} \quad(\mathbf{n}=9)$

$17.2^{\# \Delta}$

(14.6-20.6)

Vit C $\quad(n=9)$

24.0

(19.2-27.0)

No-I/R (n=9)

11.7

(7.4-17.0) 
Abbreviations: I/R-only= ischaemia/reperfusion (I/R) injury and given supplementary carbohydrates; $\mathrm{Rh}=\mathrm{I} / \mathrm{R}$ injury and given rose hip; $\mathrm{Lp}=\mathrm{I} / \mathrm{R}$ injury and given $\mathrm{L}$. plantarum and supplementary carbohydrates; Rh+Lp= I/R injury and given rose hip and $L$. plantarum; Vit C= I/R injury and given vitamin $\mathrm{C}$ and supplementary carbohydrates; No$\mathrm{I} / \mathrm{R}=$ without $\mathrm{I} / \mathrm{R}$ injury but given supplementary carbohydrates.

${ }^{*} P<0.05$ vs. No-I/R Group

\# $P<0.05$ vs. I/R-only Group

$. P<0.05$ vs. Lp Group and Vit.C Group

Figure 1. Levels of MDA (nmol/g) in the mouse caecum without injury and after I/R. The group supplemented with rose hip and L. plantarum in combination differed significantly from the I/R-only group, $\mathrm{p}=0.024$; from the $L$. plantarum alone group, $\mathrm{p}=0.03$; and from the vitamin $\mathrm{C}$ group, $\mathrm{p}=0.013$. A statistically significant difference was found between I/R-only group compared with No-I/R group, $p=0.011$. Outliers $(\mathbf{O})$ were cases with values between 1.5 and 3 box lengths from the upper or lower edge of the box. Extremes (.) were cases with values more than 3 box lengths from the upper or lower edge of the box. The box length is the interquartile range.

Figure 2. Caecal Enterobacteriaceae counts (log CFU/g content) from mice fed either experimental diet alone or supplemented with vitamin C or L. plantarum DSM 9843 and/or rose hip. The control group and the groups given $L$. plantarum alone and vitamin C significantly differed from the group treated with rose hip and lactobacilli in combination ( $\mathrm{p}=0.002$ vs control, $\mathrm{p}=0.004$ vs vit $\mathrm{C}$ and $\mathrm{p}=0.024$ vs bacteria). Between 
I/R-only group and No-I/R group there was only a small difference in caecal Enterobacteriaceae count. Outliers $(\mathbf{O})$ were cases with values between 1.5 and 3 box lengths from the upper or lower edge of the box. Extremes (.) were cases with values more than 3 box lengths from the upper or lower edge of the box. The box length is the interquartile range.

Figure 3. Caecum histology: A. I/R-only group is showing mucosal damage, congestion and edema. B. The group supplemented with rose hip and L. plantarum in combination is showing the most conservative shape of mucosa and the highest regenerative action. 